\title{
Study of the Soil-Ecological State of the Soils of the Objects of Study on the Example of the Foothill Zones of Azerbaijan in the Lesser Caucasus Under Various Crops
}

\author{
Aliyev Zakir Huseun Oglu \\ Institute of Soil Science and Agrochemistry of the National Academy of Sciences of Azerbaijan, Soil Erosion Laboratories, Baku, Azerbaijan \\ Email address: \\ zakirakademik@mail.ru \\ To cite this article: \\ Aliyev Zakir Huseun Oglu. Study of the Soil-Ecological State of the Soils of the Objects of Study on the Example of the Foothill Zones of \\ Azerbaijan in the Lesser Caucasus Under Various Crops. American Journal of Plant Biology. Vol. 6, No. 2, 2021, pp. 28-33. \\ doi: 10.11648/j.ajpb.20210602.12
}

Received: March 23, 2021; Accepted: April 15, 2021; Published: May 21, 2021

\begin{abstract}
The studies were carried out on the following types of soils, most widespread within Azerbaijan: gray-brown, gray-earth-meadow, gray-brown and mountain-gray-brown. Common to these soils is the deep penetration of humus into the soil profile and its very slow decrease down by profile. According to the results of our research, it is proved that in the soil the humus content in the $25-50 \mathrm{~cm}$ layer is from 2.00 to $2.12 \%$, and the total nitrogen is from 0.112 to $176 \%$, the content of mineral forms of nitrogen is almost identical with the previous soils, while some an increase in the content of phosphorus and exchangeable potassium relative to other studied soils. The amount of carbonates in these soils is low $\left(\mathrm{CaCO}_{3}-6.4-10.4 \%\right)$. The absorbed bases are dominated by calcium, which is $60.3-76.7 \%$ of the total exchangeable cations. The amount of exchangeable sodium in the absorbed complex is low, $2.7-4.7 \%$ of the total, while the content of exchangeable magnesium is quite high. The moisture regime of mountain-gray-brown soils is determined mainly by the amount of atmospheric precipitation and the course of evaporation of soil moisture.
\end{abstract}

Keywords: Carbonate Content, Leaching, Mountain-Brown, Gray-Brown, Gray-Meadow, Gray-Brown (Chestnut), Gray-Brown (Chestnut) Soils, Erosional Relief, Rainfed, etc

\section{Introduction}

The territory of Azerbaijan is divided into 2 large zones. The first includes the low-lying and lowland foothills, where the cultivation of crops without artificial irrigation is impossible, that is, the irrigated zone. It makes up $60 \%$ of the total area and is an agricultural facility. The rest of the mountainous regions belong to the second region with rainfed and semi-rainfed agriculture. In different periods of the twentieth century, the land fund of the republic was studied mainly by Russian soil scientists and was included in new soil-geographic zones. S. A. Zakharov, K. A. Alekperov, VV Volobuev research can find confirmation of the above opinions [6, 8, 22, 23].

Mountain brown soils are formed in the lower reaches of arid forests and shrubs. These lands were formed in the mountainous parts of the Greater and Lesser Caucasus at an altitude of $800-1200 \mathrm{~m}$, in the middle and low mountains of the Nakhchivan and Lankaran regions. Mountain brown soils form a transition between mountain gray brown soils and mountain black forest soils. Mountain brown soils are formed in arid conditions under light oak-hornbeam forests, in areas with a developed xerophytic grass cover. These soils are formed in difficult relief-hydrothermal conditions. [14, 24].

Depending on the formed ecological and geographical conditions, brown soils are divided into 3 subtypes: 1 . Washed mountain brown; 2. Typical mountain brown; 3. Carbonated mountain brown.

1. Geomorphological structure of the territory

On the territory of Azerbaijan, the Lesser Caucasus is represented by its northern part, including the Karabakh volcanic plateau. The formation of mountain folds in the Lesser Caucasus coincides with different geological eras. The period of development of the main mountaineering phase in the formation of the modern relief of the Lesser Caucasus coincides with the Pliocene, which mainly fell on the time 
when the vertical elevation of different areas was complicated by fragmentation and was rich in sedentary movements [4, 14]. Some of the large tectonic structures in the central part of the Lesser Caucasus, which is part of Azerbaijan, do not have their own shape in the relief. One of the main reasons for this is that these structures are subject to weak differential uplift in the middle mountain belt of the vast northern slope of the Lesser Caucasus in the orogenic phase, especially in its second half. Therefore, if we generally look at the surface structure of the northern slope of the Lesser Caucasus, then, despite the fact that the amplitude of the internal elevation reaches 1000-1200 $\mathrm{m}$, the entire territory resembles a wide mountain plateau. On the border of the northern and eastern foothills of the Lesser Caucasus and the Kursk bend zone, there are low monoclinic ridges located in various structural elements and composed mainly of chalk marls, limestones and partly volcanic rocks.

Starting from the western borders of Azerbaijan, the mountains of the Lesser Caucasus are surrounded by the Shahdag frontal ridge. This ridge stretches east and southeast as a result of the folding of the Lesser Caucasus mountains. In the Azerbaijan part of the Lesser Caucasus, the following types of relief can be distinguished:

2. Glias-erosional relief.

This type of relief is represented by troughs and karsts in the valleys. Forming this type of rail efa is strictly limited on the northern slopes of Gamishdag, Shahdag and Murovdag. In the unexplored part of the Lesser Caucasus N. V. According to Dumitrashko, the glacial relief mainly covers large areas in Zangezur, the southern part of Goych and the Akhalkalaki plateau. Different researchers have different opinions about the glaciation of the Lesser Caucasus for different reasons: S. B. Zon came to the conclusion that four ice ages played a key role in the formation of the landscape [6, 24].

3 . Relief formed as a result of smoothing ancient surfaces. The main characteristic feature of this type of relief is that tectonic features are insecure in their response to substrates and lithology. It should also be noted that this landform is rarely found in large areas with which to compare. N. V. According to Dumitrashko, the lower layers of this type of relief are not of subaerial denudation, but of abrasion origin, which is associated with fluctuations in the level of the upper Tertiary seas $[1,9]$.

4. Rock-tectonic mountain-erosion type of relief. It usually includes a group of terrain types. The main feature for them is the elements that determine the tectonics and lithological composition of the relief. Depending on the lithological composition of the substrate, one or another tectonic structure leads to the formation of a number of relief forms.

5. Finally, we can see young forms of lava origin (Pliocene-IV age), covering a very small area of the Lesser Caucasus. According to the features identified by Sh. A. Azizbekov, this form of relief, being very young, was called a kind of "armored relief" and retained its original features better than the influence of exogenous processes [8, 12, 18].

Below are the main soil and ecological characteristics of these soils, which play an important role in the life of soil microorganisms.

\section{Gray-brown Soil}

The area of gray-brown soils in Azerbaijan is 710 thousand hectares or $8.3 \%$ of the total area of the republic. Wheat, corn, alfalfa, here, olives and vegetables grow well on the soil. The parent rocks of the hilly-ridge part of the territory occupied by gray-brown soils are characterized by the presence of alluvial and deluvial bedrock saline rocks. The flat part of the territory is covered with deluvial sediments from 2 to $5 \mathrm{~m}$ thick. The climate is sharply arid, with long summers, short and warm winters, the average annual temperature is $13-15^{\circ} \mathrm{C}$, the annual amount of precipitation is within 173-237 $\mathrm{mm}$, the maximum amount of precipitation falls in the autumn, as well as in the spring). [2, 4, 19, 21]

The temperature regime of gray-brown soils is characterized by the following features: the minimum temperature values (4$6^{\circ} \mathrm{C}$ ) are observed in the $0-40 \mathrm{~cm}$ layer in January, February and December. The maximum soil temperature $\left(30-32^{\circ} \mathrm{C}\right)$ from the surface is observed in the summer months. The active temperature period is 240-250 days.

According to the state of natural moisture, gray-brown soils are distinguished by the presence of a long drying period. The fallout of a relatively large amount of atmospheric precipitation in spring and autumn at relatively low temperatures contributes to a noticeable increase in the moisture content in the upper soil layer. The moisture content in the soil profile remains practically unchanged here. The gray-brown soils of the experimental site are characterized by the following soil-ecological properties. The amount of humus in the upper layers of soils varies from 1.98 to $2.25 \%$, and the total nitrogen is $0.156-0.175 \%$, remaining the highest under alfalfa. The content of easily assimilable forms of nutrients in these soils is very low, where in the soil profile $\mathrm{N}-\mathrm{NO}_{3}$ varies from 5.3 to $6.7 \mathrm{mg} / \mathrm{kg}$ soil, and ammoniacal nitrogen (N-NH) 6.7-9.3 $\mathrm{mg}$, while the amount of mobile phosphorus ranges from 5.8 to $7.8 \mathrm{mg}$, and exchangeable potassium is $162-207 \mathrm{mg} / \mathrm{kg}$ of soil. The amount of striped soil based in gray-brown soils is quite high, in the soil profile it varies from 25.7 to $30.2 \mathrm{mg}$ equivalent per $100 \mathrm{~g}$ of soil, in which exchangeable calcium (53.7-62.7\%) has an advantage. the content of exchangeable magnesium is also high, amounting to $30.2-39 \%$ of the total amount of cations, while sodium is from 6.5 to $7.2 \%$. In terms of texture, the graybrown soils of Apsheron are light and medium loamy. [20, 23]. The soils are calcareous $\left(\mathrm{CaCO}_{3}-9.6-13.9 \%\right)$, the reaction of the soil medium is slightly alkaline and alkaline, the $\mathrm{pH}$ value of the aqueous suspension is -7.8-8.1.

Gray-brown soils genetically occupy a transitional position between desert-steppe and sierozem soils.

\section{Serozem-meadow Soils}

Serozem-meadow soils occupy 885 thousand hectares or $10.3 \%$ of the republic's area. Wheat, corn, cotton, alfalfa and other agricultural crops grow well on these soils. This type of soil develops in a dry climate, periodic and constant capillary moistening with groundwater. [21] 
In these soils, the meadow process dominates over the steppe, the groundwater level is found at a depth of 1 to $3 \mathrm{~m}$. Serozem-meadow soils in the upper horizons contain oozy particles. In the subsurface horizons of these soils, the beginning of about the formation of the illuvial horizon.

The heavy texture of the plow horizon of gray-meadow soils often "is the cause of crust formation. [25]

The gray-meadow soils of the experimental site are characterized by the following soil and ecological conditions: the humus content in the soil profile varies from 1.36 to $2.32 \%$, and the total nitrogen content from 0.086 to $0.185 \%$. The amount of nitrate nitrogen $\left(\mathrm{N}-\mathrm{NO}_{3}\right)$ ranges from 5.4 to $7.3 \mathrm{mg} / \mathrm{kg}$, and ammonia nitrogen -6.5-9.2 mg, mobile phosphorus varies within 6.3-17.5 $\mathrm{mg}$, and exchangeable potassium -185-236 mg / $\mathrm{kg}$ of soil.

The amount of absorbed bases is high, in the composition of which calcium (50.2-56.5\%) and magnesium (39.1-43.6\%) predominate, while the amount of exchangeable sodium is from 5.4 to $6.9 \%$ of the total the amount of absorbed bases.

The content of carbonates in the soil profile is more evenly distributed and changes in the soil profile in a narrow range of $11.5-13.9 \%$, the reaction of the soil medium is slightly alkaline and alkaline, the $\mathrm{pH}$ of the aqueous suspension is 7.7-8.1.

\section{Gray-brown (chestnut) Soils}

The dry steppe zone is located at an altitude of 200-600 m above sea level, it covers a strip of low mountains, foothills and foothill plains of the Greater and Lesser Caucasus. The parent rocks of these soils are in most cases deluvial, proluvial deluvial loamy sediments and sandy-pebble deposits.
In the dry steppe zone of Azerbaijan, the average annual temperature is $10-12^{\circ} \mathrm{C}$. The characteristic features of the dry steppe zone are pronounced aridity and poor vegetation cover.

Among the gray-brown (chestnut) soils of Azerbaijan, mountain soils, on which rain-fed agriculture is developed, and flat soils, on which only irrigated agriculture is possible, stand out sharply. Gray-brown (chestnut) soils are more common and account for $27.4 \%$ of the total area of the republic. More than $80 \%$ of chestnut plain soils are developed for various agricultural crops and are the main fund of the field lands of the irrigated zone.

Gray-brown (chestnut) soils can be referred to heavy loamy soils, the content of humus in a half-meter layer of soils varies from 1.12 to $2.97 \%$, and total nitrogen - 0.096 $0.221 \%$. The amount of nitrates varies from 5.3 to $7.5 \mathrm{mg}$, absorbed ammonia from 6.4 to $9.7 \mathrm{mg} / \mathrm{kg}$ of soil. The content of mobile phosphorus and exchangeable potassium in these soils varies, respectively, $10.3-19.3 \mathrm{mg}$ to $197-227 \mathrm{mg} /$ $\mathrm{kg}$ of soil. The amount of absorbed bases is $20.8-28.4 \mathrm{mg} /$ $\mathrm{kg}$ of soil, with a predominance of absorbed calcium (60.5$72.7 \%$ ), the amount of exchangeable sodium is low -3.6$6.7 \%$ of the total.

Gray-brown (chestnut) soils are highly carbonate. The amount of $\mathrm{CaCO}_{3}$ varies from 15.3 to $19.3 \%$, the reaction of the soil medium is slightly alkaline, the $\mathrm{pH}$ of the aqueous suspension is 7.6-7.8.

Mountain gray-brown soils. Mountain-gray-brown soils in the republic are mainly confined to a relatively arid belt of light forests ranging from 700 to $1200 \mathrm{~m}$ above sea level and the middle region of mountains and foothills. The total area of these soils is $11.5 \%$ of the total area of the republic

Table 1 Soil-ecological characteristics of the soils of the objects of study.

\begin{tabular}{|c|c|c|c|c|c|c|c|}
\hline \multirow{2}{*}{ Soil and land } & \multirow{2}{*}{ Depth cm } & \multirow{2}{*}{ Humus, } & \multirow{2}{*}{ Total nitrogen,\% } & \multirow{2}{*}{$\mathrm{NMO}_{3}$} & \multicolumn{3}{|c|}{ mg / kg soil } \\
\hline & & & & & $\mathrm{K}^{-\mathrm{NO}_{3}}$ & $\mathrm{P}_{2} \mathrm{O}_{5}$ mobile & $\mathrm{K}_{2} \mathrm{O}$ exchange \\
\hline 1 & 2 & 3 & 4 & 5 & 6 & 7 & 8 \\
\hline \multirow{2}{*}{$\begin{array}{l}\text { Gray-brown irrigated, under } \\
\text { winter wheat }\end{array}$} & $0-25$ & 1,89 & 0,156 & 5,3 & 7,9 & 6,6 & 196 \\
\hline & $25-50$ & 0,90 & 0,079 & 5,7 & 6,7 & 5,2 & 162 \\
\hline \multirow{2}{*}{ Under the corn } & $0-25$ & 2,05 & 0,162 & 6,2 & 8,3 & 7,8 & 207 \\
\hline & $25-50$ & 1,02 & 0,089 & 5,9 & 6,9 & 6,3 & 170 \\
\hline Under the alfalfa & $0-25$ & 2,25 & 0,175 & 6,7 & 9,3 & 6,9 & 197 \\
\hline \multirow{2}{*}{$\begin{array}{l}\text { Serozem-meadow, irrigated, } \\
\text { under wheat }\end{array}$} & $0-25$ & 2,25 & 0,176 & 6,7 & 8,0 & 17,2 & 212 \\
\hline & $25-50$ & 1,76 & 0,086 & 5,4 & 6,5 & 9,0 & 196 \\
\hline \multirow{2}{*}{ Under the corn } & $0-25$ & 2,27 & 0,178 & 7,3 & 9,2 & 17,5 & 215 \\
\hline & $25-50$ & 1,36 & 0,09 & 5,0 & 6,7 & 9,2 & 185 \\
\hline \multirow{2}{*}{ Under the alfalfa } & $0-25$ & 2,32 & 0,185 & 6,5 & 8,5 & 16,9 & 236 \\
\hline & $25-50$ & 1,78 & 0,097 & 5,7 & 6,9 & 6,3 & 197 \\
\hline Gray-brown under wheat & $0-25$ & 2,89 & 0,215 & 7,5 & 9,7 & 18,5 & 225 \\
\hline \multirow{2}{*}{ Under the corn } & $25-50$ & 1,15 & 0,096 & 5,3 & 7,2 & 10,6 & 200 \\
\hline & 2 & 3 & 4 & 5 & 6 & 7 & 8 \\
\hline \multirow{2}{*}{ Under the alfalfa } & $0-25$ & 2,97 & 0,221 & 6,0 & 8,9 & 19,3 & 215 \\
\hline & $25-50$ & 1,21 & 0,125 & 5,7 & 6,4 & 10,3 & 197 \\
\hline \multirow{2}{*}{$\begin{array}{l}\text { Mountain gray-brown under } \\
\text { wheat }\end{array}$} & $0-25$ & 3,21 & 0,256 & 6,7 & 8,7 & 19,7 & 234 \\
\hline & $25-50$ & 2,12 & 0,136 & 5,3 & 7,6 & 9,8 & 207 \\
\hline \multirow{2}{*}{ Under the corn } & $0-25$ & 3,05 & 0,240 & 6,4 & 9,5 & 21,2 & 227 \\
\hline & $25-50$ & 2,00 & 0,112 & 5,0 & 7,3 & 14,7 & 197 \\
\hline \multirow{2}{*}{ Under the alfalfa } & $0-25$ & 3,36 & 0,265 & 6,0 & 10,7 & 19,6 & 215 \\
\hline & $25-50$ & 2,27 & 0,176 & 5,2 & 18,3 & 11,2 & 186 \\
\hline
\end{tabular}


Table 1. Continue.

\begin{tabular}{|c|c|c|c|c|c|c|c|c|}
\hline \multirow{2}{*}{ Soil and land } & \multirow{2}{*}{$\begin{array}{l}\text { Amount absorbed base, mg } \\
\text { equivalent } 100 \mathrm{~g} \text { of soil }\end{array}$} & \multicolumn{3}{|c|}{ \% от суммы \% from the sum } & \multirow{2}{*}{$\begin{array}{l}\mathrm{CaCO}_{3} \\
\text { by } \mathrm{CO}_{2} \\
\end{array}$} & \multicolumn{2}{|c|}{ Particle size, $\mathbf{m m}$} & \multirow{2}{*}{$\begin{array}{l}\text { pH of water } \\
\text { suspensions }\end{array}$} \\
\hline & & $\mathbf{C a}$ & Mg & $\mathbf{N}_{3}$ & & $<0,001$ & 0,01 & \\
\hline 1 & 9 & 10 & 11 & 12 & 13 & 14 & 15 & 16 \\
\hline \multirow{2}{*}{$\begin{array}{l}\text { Gray-brown irrigated, under } \\
\text { winter wheat }\end{array}$} & 26,7 & 60,2 & 33,9 & 6,9 & 9,6 & 27,4 & 59,6 & 7,9 \\
\hline & 28,3 & 61,4 & 31,4 & 7,2 & 12,3 & 22,7 & 62,7 & 8,1 \\
\hline \multirow{2}{*}{ Under the corn } & 27,9 & 62,7 & 30,2 & 7,1 & 10,7 & 30,2 & 68,5 & 7,8 \\
\hline & 30,2 & 60,9 & 32,1 & 7,0 & 13,6 & 24,5 & 60,7 & 8,0 \\
\hline Under the alfalfa & 25,7 & 57,5 & 36,0 & 6,5 & 11,7 & 31,4 & 59,7 & 8,0 \\
\hline \multirow{2}{*}{$\begin{array}{l}\text { Serozem-meadow, irrigated, } \\
\text { under wheat }\end{array}$} & 31,2 & 56,5 & 38,1 & 5,4 & 11,5 & 22,7 & 58,6 & 7,7 \\
\hline & 29,6 & 50,2 & 43,6 & 6,2 & 12,3 & 25,4 & 54,9 & 8,0 \\
\hline \multirow{2}{*}{ Under the corn } & 32,7 & 54,4 & 39,6 & 6,0 & 10,9 & 23,9 & 56,9 & 7,8 \\
\hline & 30,9 & 51,2 & 42,1 & 6,7 & 13,4 & 30,8 & 50,4 & 7,9 \\
\hline \multirow{2}{*}{ Under the alfalfa } & 33,7 & 52,5 & 41,1 & 6,4 & 11,7 & 20,7 & 57,4 & 7,8 \\
\hline & 31,9 & 50,4 & 42,7 & 6,9 & 13,9 & 26,5 & 51,6 & 8,4 \\
\hline Gray-brown under wheat & 27,6 & 67,2 & 28,2 & 3,6 & 17,3 & 25,7 & 57,6 & 7,6 \\
\hline \multirow{2}{*}{ Under the corn } & 24,5 & 64,5 & 29,4 & 6,1 & 16,9 & 21,9 & 59,9 & 7,8 \\
\hline & 9 & 10 & 11 & 12 & 13 & 14 & 15 & 16 \\
\hline \multirow{2}{*}{ Under the alfalfa } & 23,4 & 69,7 & 6,0 & 4,3 & 17,5 & 24,4 & 56,2 & 7,8 \\
\hline & 20,8 & 62,5 & 31,8 & 6,7 & 19,3 & 23,2 & 57,8 & 7,7 \\
\hline \multirow{2}{*}{$\begin{array}{l}\text { Mountain gray-brown under } \\
\text { wheat }\end{array}$} & 31,5 & 69,7 & 27,6 & 2,7 & 6,4 & 27,3 & 63,0 & 7,7 \\
\hline & 28,9 & 60,3 & 36,1 & 3,6 & 10,2 & 26,4 & 62,7 & 7,9 \\
\hline \multirow{2}{*}{ Under the corn } & 33,6 & 75,8 & 21,8 & 3,4 & 5,9 & 296,5 & 64,6 & 7,6 \\
\hline & 30,7 & 62,9 & 32,6 & 4,5 & 8,7 & 24,2 & 60,5 & 7,9 \\
\hline \multirow{2}{*}{ Under the alfalfa } & 33,9 & 76,7 & 20,4 & 2,9 & 7,2 & 27,5 & 62,9 & 7,8 \\
\hline & 29,6 & 74,4 & 30,9 & 4,7 & 10,4 & 24,7 & 60,7 & 8,0 \\
\hline
\end{tabular}

Gray-brown (chestnut) soils are more common and account for $27.4 \%$ of the total area of the republic. More than $80 \%$ of chestnut plain soils are developed for various agricultural crops and are the main fund of the field lands of the irrigated zone.

Gray-brown (chestnut) soils can be referred to heavy loamy soils, the content of humus in a half-meter layer of soils varies from 1.12 to $2.97 \%$, and total nitrogen - 0.096 $0.221 \%$. The amount of nitrates varies from 5.3 to $7.5 \mathrm{mg}$, absorbed ammonia from 6.4 to $9.7 \mathrm{mg} / \mathrm{kg}$ of soil. The content of mobile phosphorus and exchangeable potassium in these soils varies, respectively, $10.3-19.3 \mathrm{mg}$ to $197-227 \mathrm{mg} /$ $\mathrm{kg}$ of soil. The amount of absorbed bases is $20.8-28.4 \mathrm{mg} /$ $\mathrm{kg}$ of soil, with a predominance of absorbed calcium (60.5$72.7 \%$ ), the amount of exchangeable sodium is low -3.6$6.7 \%$ of the total.

Gray-brown (chestnut) soils are highly carbonate. The amount of $\mathrm{CaCO}_{3}$ varies from 15.3 to $19.3 \%$, the reaction of the soil medium is slightly alkaline, the $\mathrm{pH}$ of the aqueous suspension is 7.6-7.8.

Mountain gray-brown soils. Mountain-gray-brown soils in the republic are mainly confined to a relatively arid belt of light forests ranging from 700 to $1200 \mathrm{~m}$ above sea level and the middle region of mountains and foothills. The total area of these soils is $11.5 \%$ of the total area of the republic.

Forests covering mountain-gray-brown soils, as well as beech forests, are of great water conservation (water retention) and soil protection significance. Soils are formed in a relatively dry, moderately warm climate with an average annual temperature of $8-11^{\circ} \mathrm{C}$ and a maximum summer temperature of up to $20^{\circ} \mathrm{C}$. The average annual rainfall does not exceed $360-600 \mathrm{~mm}$. In the soil profile, humus is morphologically separated at a depth of $6.0-6.5 \%$, and carbonates at a depth of $80-90 \mathrm{~cm}$. In order to see this change more clearly, areas were selected according to the degree of soil erosion in the plantations and hayfields of the areas formed by carbonate-washed mountain soils, soil sections were made, detailed information on their morphological structure and agrochemical composition was obtained. The following is a morphological description of the profile of section 1:

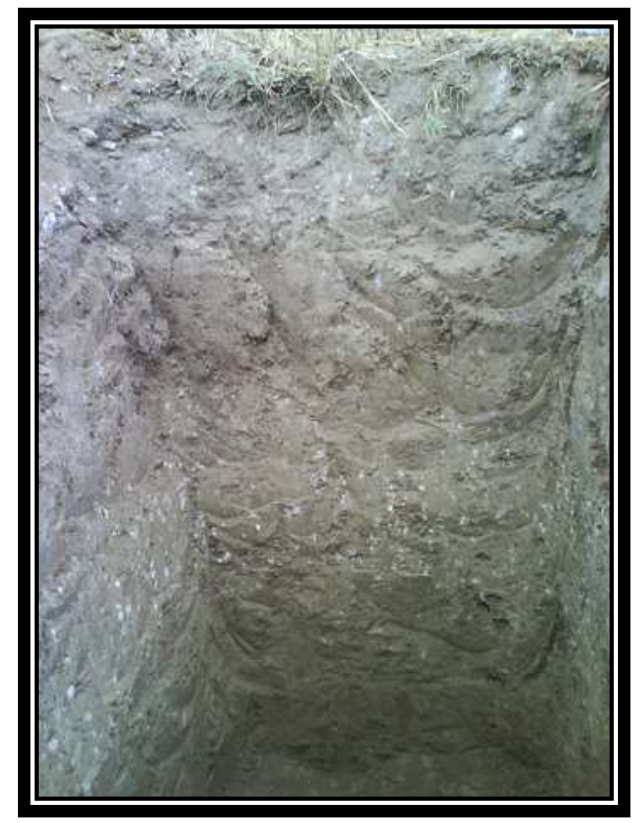




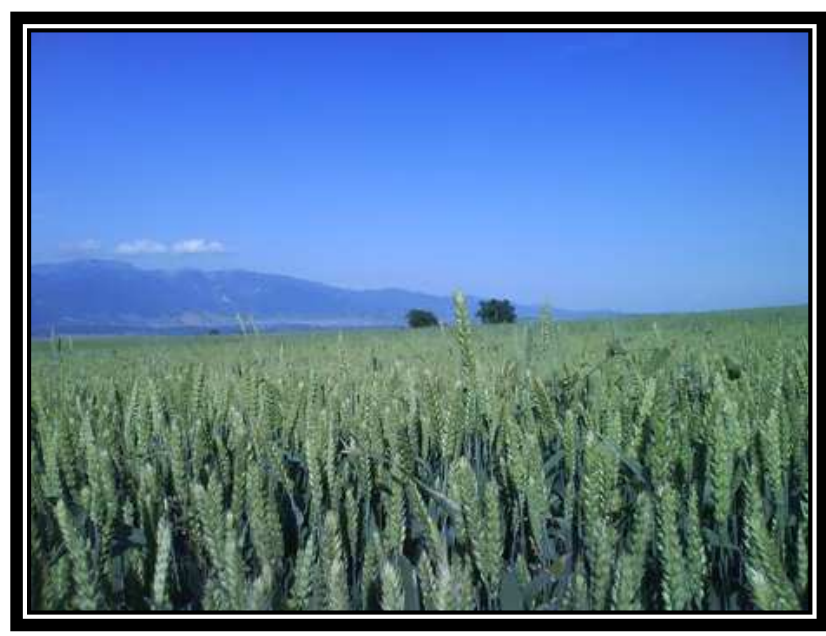

b

Figure 1. Shamkir region carbonate mountain-brown soils (under grain).

The composition of the silt fraction varies between $24.0 \pm$ $2.4 \%$ in the top layer and $56.8 \pm 4.9 \%$ in the physical clay. The amount of sludge particles in the skin increases, especially in the Bt layer (Table 1).

Section 2

Avz 0-12 heavy and medium clayey, dark brown, granularsoft, soft, many loop-shaped plant roots and worm tracts, moist, gradual transition;

Avz / B12-34 medium clayey, brown, broken topavarigranular, relatively hard, small rock fragments, sparse roots, moist, gradual transition;

Btca 34-61 lightly clayey, light brown, weakly loamy, relatively hard, numerous small rock fragments, moist, clear transition;

Btca / C 61-90 medium clayey, light brown, broken small nuts, soft, rocky, moist, gradual transition;

Ccal 90-113 medium clayey, light brown, broken finegrained, medium-sized, small rock fragments, low moisture, gradual transition;

Ccal / D113-147 top layer repetition, transition to floor rock.

\section{Conclusion}

As can be seen from the description of sections of carbonate-washed mountain-black soils, the main reason for this is the parallel anthropogenic impact on arable lands, as well as the intensity of man-made impact (heavy tonnage agricultural machinery). This is due to the fact that during the plowing, sowing and cultivating works in the fields, heavy tonnage of agricultural crops is spread by spraying the surface of the crop. As a result, surface washing intensifies and covers large areas and reduces productivity.

In such conditions, the failure to implement special soilprotective agro-technical control measures leads to the rapid development of the process of clay in the lower layers of the soil, and the latter leads to increased erosion and leaching of arable soil.

\section{References}

[1] Agaev N. A. Agrochemical grouping of soils in the Lesser Caucasus by the content of nutrients and their effect on potato productivity. Report VASKHNIL No. 5, 1989, 15-18 pages.

[2] Genesis, geography and efficient use of forest lands of Azerbaijan. Works of the Institute of Geography of ANAS; volume XXV, Baku, 1990, pp. 51-53.

[3] Land map of Azerbaijan. 1991, 1: 600000

[4] Agroclimatic Atlas of the Republic of Azerbaijan. Baku, 1993, 20-22 pages.

[5] Alekperov K. A. Protection of soils from erosion in Azerbaijan. SSR. 1979, 220 pp.

[6] Alekperov K. A. Soil erosion map and land protection. Moscow, 1980.219 p.

[7] Akimtsev V. V. Soils of the Ganja region. 1928, 107 pp.

[8] Antonov B. A. Small Caucasus. In the book. "Geomorphology of Azerbaijan" Publishing house of the Academy of Sciences of Azerbaijan. SSR, Baku, 1959, 193 p.

[9] Azizbekov Sh. A. Geology and petrography of the northeastern part of the Lesser Caucasus. Institute of Geology. Gubkin AN Azerb. SSR. Baku, 1947, 47 p.

[10] Babayeva K. M. and others; Surface improvement of eroded pastures around Gadabay region. Scientific fund of the Institute of Soil Science and Agrochemistry. Baku, 2014, 55 pages.

[11] Gulahmedov A. X. Land cover of Ilich Yolu collective farm, Slavyanka village, Gadabay region and ways of its efficient use. Scientific fund of the Institute of Soil Science and Agrochemistry. Baku, 1980, 26 pages.

[12] Ibrahimov AA Study of erosion in mountain-meadow and mountain-forest zones of Shamkhor (Shamkir) and Gadabay regions. Scientific fund of the Institute of Soil Science and Agrochemistry Baku, 1972, 170 pages.

[13] Ibrahimov AA Adverse effects of soil erosion on the ecological situation in Azerbaijan and ways to prevent it (effective use of eroded lands in Azerbaijan v) Proceedings of the Institute of Erosion and Irrigation. Volume II. Baku, 1998, pp. $40-43$

[14] Molchanov A. A. Forest and climate. Ed. "AN SSR". Moscow, 1962, $127 \mathrm{p}$.

[15] Mustafayev HM Measures to combat water and wind erosion. Baku, 1978, $228 \mathrm{p}$

[16] Mustafayev X. M. Soil erosion and control measures. Azerbaijan State Publishing House, Baku, 1974, 175 p.

[17] Braude I. D. Soil erosion, drought and control of them in the Central Administrative Center, Nauka Publishing House, Moscow, 1965, $104 \mathrm{p}$.

[18] Williams V. R., General agriculture with the basics of soil science, S / khozgiz, 1931, 375 p.

[19] Volobuev V. R. Soils and climate. Ed. AN. Azerb. 1953, 236 pp. 
[20] Volobuev V. R. Soil ecology. Ed. AN Azerb. SSR, Baku, 1963, 259 s.

[21] Zakharov S. A. Fighting forest and steppe in the Caucasus. Soil science. No. 4, 1935, pp. 51-55.

[22] Zaslavsky M. N. Soil erosion and slope agriculture. Chisinau, $1966,318 \mathrm{p}$.

[23] Zeynalov A. K. Forest soils of the Murovdag ridge of the Lesser Caucasus. "Izv. AN Azerb. SSR", 1949, No. 1, 70-74p.
[24] Zonn S. B. Soil moisture and forest plantations. Ed. AN SSR. Moscow, 1959, $168 \mathrm{p}$.

[25] Ostrovski Y., Aliyev Z., et al. Using GIS programs in the study of soil erosion in Azerbaijan and determining the conditions for their protection. Educational materials. Ed. ITP. Poland, $2010,117 \mathrm{p}$. 